(C) 2022, The Authors. Published by Elsevier Inc. and Fass Inc. on behalf of the American Dairy Science Association ${ }^{\circledR}$. This is an open access article under the CC BY license (http://creativecommons.org/licenses/by/4.0/).

\title{
Effects of transport age and calf and maternal characteristics on health and performance of veal calves
}

\author{
F. Marcato, ${ }^{1,2 *}$ H. van den Brand, ${ }^{1} \odot$ B. Kemp, ${ }^{1} \odot$ B. Engel, ${ }^{3} \odot$ S. K. Schnabel, ${ }^{3} \odot$ F. A. Hoorweg, ${ }^{2}$ \\ M. Wolthuis-Fillerup, ${ }^{2}$ () and K. van Reenen ${ }^{2}$ (1) \\ ${ }^{1}$ Adaptation Physiology Group, Department of Animal Sciences, Wageningen University \& Research, PO Box 338, 6700 AH Wageningen, \\ the Netherlands \\ ${ }^{2}$ Wageningen Livestock Research, Wageningen University \& Research, PO Box 338, 6700 AH Wageningen, the Netherlands \\ ${ }^{3}$ Biometris, Wageningen University \& Research, PO Box 16, 6700 AA Wageningen, the Netherlands
}

\section{ABSTRACT}

The objective of this study was to investigate effects of calf transport age (14 vs. $28 \mathrm{~d}$ ) and calf (e.g., sex and breed) and dam characteristics (e.g., parity and ease of birth) on health and performance of veal calves until slaughter age. Calves $(\mathrm{n}=683)$ originated from 13 dairy farms in the Netherlands and were transported at either 14 or $28 \mathrm{~d}$ of age from the dairy farm to 8 Dutch veal farms. A health assessment of calves was performed on a weekly basis at the dairy farm and in wk 2, 10, 18, and 24 at the veal farm. Body weight of calves was measured on a weekly basis at the dairy farm and upon arrival at the veal farm. At the veal farm, use of antibiotics and other medicines during the rearing period (both at herd and individual level) was recorded and carcass weights were obtained from the slaughterhouse. Body weight upon arrival $(\Delta=11.8$ $\mathrm{kg})$ and carcass weight at slaughter $(\Delta=14.8 \mathrm{~kg})$ were greater, and mortality risk $(\Delta=-3.1 \%)$ and prevalence of animals treated with medicines other than antibiotics (e.g., antiinflammatories, multivitamins, and anticoccidial drugs; $\Delta=-5.4 \%$ ) were lower in calves transported at $28 \mathrm{~d}$ compared with calves transported at $14 \mathrm{~d}$. Crossbreds other than Belgian Blue $\times$ Holstein Friesian received a higher number of individual treatments with antibiotics and other medicines $(\Delta=$ $14.8 \%$ and $\Delta=15.1 \%$, respectively) at the veal farm compared with Belgian Blue $\times$ Holstein Friesian calves. These findings suggest that calves transported at $28 \mathrm{~d}$ were more robust compared with calves transported at $14 \mathrm{~d}$.

Key words: veal calf, transport age, health, performance

Received April 21, 2021.

Accepted October 4, 2021.

*Corresponding author: francesca.marcato@wur.nl

\section{INTRODUCTION}

In the Netherlands, as well as in other European countries, veal calves are collected from dairy farms and are transported to a collection center before entering the veal sector (Damiaans et al., 2019). At the collection center, calves are sorted by BW, breed, or conformation and thereafter they are transported to a veal farm. The legally required minimum age at which calves might be transported and enter the Dutch veal sector is $14 \mathrm{~d}$ (SBK, 2018). Upon arrival at the veal farm, calves frequently exhibit health problems (Bähler et al., 2012; Pempek et al., 2017; Renaud et al., 2018), some of which are associated with a greater risk of mortality (Pempek et al., 2017; Renaud et al., 2018). The high disease and mortality rates in veal calves are likely related to the various challenges these animals are exposed to, including transport, irregular meals, and mixing with other animals (Pempek et al., 2017). Most importantly, in comparison with older animals, young calves have a greater risk of infection with pathogens, because of an immature immune system (Autio et al., 2007; Pardon et al., 2015), and consequently, they could be considered less robust than older animals. Robustness can be defined as the ability of calves to cope with environmental challenges and to bounce back rapidly when challenges occur (Colditz and Hine, 2016). Robust calves are better equipped to cope with endemic infections and fight diseases and thus probably have a lower need for antimicrobials. A companion paper (Marcato et al., 2022) looked at potential early indicators of robustness measured in blood of calves, including immunoglobulins (Pardon et al., 2015; Goetz et al., 2021) and hematological parameters (von Konigslow et al., 2020). The current study will examine the clinical health status and mortality risk of calves, and will quantify the number of antibiotic and other medical treatments (e.g., antiinflammatories, multivitamins, and anticoccidial drugs) as ultimate measures 
of robustness (Marcato et al., 2018; de Almeida et al., 2019).

In the present experiment, calves were transported at 14 or $28 \mathrm{~d}$ of age from a dairy farm to a veal farm. The main aim of the current study was to examine, in a longitudinal fashion, effects of transport age on measures of health and performance of calves at the veal farm. According to literature (Chase et al., 2008; Hulbert and Moisá, 2016), calves around 14 to $20 \mathrm{~d}$ of age are in the middle of the "immune gap period," whereas older calves, around 4 wk of age, appear to have already started to develop their adaptive immune system. Thus, we were interested to have a measurement beyond wk 2 to examine whether or not calves are still in the immune gap window or whether they have already started with their endogenous production of antibodies and thus might be more robust and show fewer health problems. In addition, this study aimed to investigate extent to which calf (breed and sex) and dam (parity and ease of birth) characteristics might affect robustness of veal calves. Recent studies provided support for the relevance of these characteristics for health and performance of beef cattle (Diana et al., 2021) and female offspring of dairy cows (Astiz et al., 2014; Pinedo and De Vries, 2017). The overall hypothesis of the current study was that calves transported at $28 \mathrm{~d}$ of age from the dairy farm to the veal farm were more robust, had a greater adaptive capacity, and therefore, showed fewer clinical health problems compared with calves transported at $14 \mathrm{~d}$ of age. An improved health status of calves transported at $28 \mathrm{~d}$ of age might contribute to a lower number of medical treatments and a greater carcass weight compared with calves transported at $14 \mathrm{~d}$ of age.

\section{MATERIALS AND METHODS}

\section{Experimental Design}

The experiment was conducted between March 2019 and May 2020, and was approved by the Central Committee on Animal Experiments (the Hague, the Netherlands; approval number 2017.D-0029). The experimental design was a matrix consisting of 13 dairy farms and 8 veal farms (see Marcato et al., 2022, for details). The allocation of calves to the respective age groups (14 and $28 \mathrm{~d}$ ) was done by the researchers during their weekly visits on the dairy farms. The dairy farms included in this experiment were selected in collaboration with the Netherlands Agricultural and Horticultural Association (LTO Nederland). Farmers participated in the experiment on a voluntary basis. For the recruitment, we looked for dedicated farmers, willing to participate, with a dairy farm size large enough to provide enough calves to be included in the experiment on a weekly basis. The various calf rearing and management systems applied on the dairy farms that participated in the current experiment largely covered the variation that is present in the Dutch dairy sector. In short, calves $(\mathrm{n}=683)$ originated from 13 different Dutch dairy farms. Within each farm, calves were allocated to the age treatment group (labeled 14 or $28 \mathrm{~d}$ ) based on the week of birth to avoid confounding between the experimental factor age and the effects of dairy farm of origin and veal farm, and to make sure that calves from both age groups and from all dairy farms of origin entered the veal farm at the same moment. Calves of all 13 dairy farms were transported to 8 veal farms. At each transport day, 2 transporters collected calves from the dairy farms (6 and 7 dairy farms, respectively) and brought these directly to the veal farm, meaning that for each veal farm in total 4 transports were performed. As indicated in the companion paper (Marcato et al., 2022), this experimental design resulted in variation in actual age between calves within each transport age group; the actual age of calves transported at $14 \mathrm{~d}$ ranged between 14 and $22 \mathrm{~d}$, and that of calves transported at $28 \mathrm{~d}$ ranged between 28 and 36 d. Since a total of 13 dairy farm and 8 veal farms took part in the current experiment, the likelihood of a systematic difference between transport age groups due to factors other than age was deemed negligible (see Marcato et al., 2022, for further reflections on the experimental design).

\section{Descriptive Statistics}

Over the course of our study, the experiment included 714 calves, representing all surplus calves intended for veal production. Some of these calves died while on the dairy farm, and some were not fit for transport and were, therefore, not transported to the veal farms (but observations obtained in these animals at the dairy farm remained an integral part of the experiment). In line with the criteria stipulated by the national branch organization of the Dutch veal industry (SBK), a calf was considered unfit for transport when it did not meet at least one of the following requirements: $\mathrm{BW}>36$ $\mathrm{kg}$; age: minimum $14 \mathrm{~d}$; no signs of disease and injury (SBK, 2018). Thus, a total of 363 calves allocated to the 14-d treatment group, and 320 calves allocated to the 28-d treatment group were transported to the veal farms. On average, 85 (range: 70-100) calves were transported to each of 8 veal farms. Out of 683 calves, 508 were males and 175 were females. With regard to breed, 246 calves were Belgian Blue $\times$ Holstein Friesian crossbreds, 235 calves were Holstein Friesians, and 202 calves were crossbreds other than Belgian Blue $\times$ Holstein Friesian. With regard to parity, 90 calves were 
born from first-parity cows, 165 from second-parity cows, 151 from third-parity cows, and 252 from cows with parity 4 or greater. With regard to housing conditions at the dairy farm, $41 \%$ of calves were housed in a single box, $26 \%$ were housed in an igloo ( 1 calf per igloo), $13 \%$ stayed with their mothers in the calving pen, $14 \%$ were housed in a single box during the first week after birth and then relocated to a group pen (5 to 6 calves per pen) and $6 \%$ were housed first in an individual pen and then in an igloo. Both calves and cows did not receive any preventive medicines, such as vaccines, on source dairy farms. Calves were also not vaccinated at the veal farm operations.

\section{Sample Size Calculation}

The number of experimental units required in the present study was based on a power analysis. As reported in our companion paper (Marcato et al., 2022), the number of calves aimed for per treatment group was based on calculations performed in previous studies on veal calves under experimental and commercial conditions (Engel et al., 2016; Marcato et al., 2020). The variance used in the power calculations underlying the present study was the residual within farm variance. For proportions, the "residual" variance was the multiple of the Bernoulli variance and the largest value was obtained for an expected proportion of 0.5. It was assumed that dependence was adequately covered by random main effects for farms, and that fixed effects were largely within farms. The minimum difference of interest between treatment groups was specified as a fraction 0.3 of the residual standard deviation, the desired power was 0.90 , and the level of significance for a 2 -sided test was set at 0.05 . These values resulted in a sample size of 235 per age group, 470 in total when a fully balanced design would be assumed. To be able to deal with an unbalanced design we aimed for a surplus of animals.

\section{Health Assessment}

Health assessments of calves were performed at the dairy farms on a weekly basis until and including the day before transport. All calves were examined individually using protocol 1 (Supplemental Table S1, https://doi.org/10.6084/m9.figshare.17024522.v1, van Reenen, 2021). The health assessment was performed on a weekly basis to monitor the health status of calves transported from the dairy farm to the veal farm at different ages on a cross-sectional basis, rather than documenting in detail changes in health status of calves over time (e.g., on a day-to-day basis). The choice of weekly health checks was also based on practical feasi- bility, but we appreciate that this approach might be a limitation of the current study, and that taking into account the daily variation of health problems in calves would be a valuable addition to research in this area. During each clinical assessment, the rectal temperature was also recorded. At the veal farm, health assessments took place in wk $2,6,10,18$, and 24 posttransport. In wk 2 posttransport, calves were housed individually and their health was examined using protocol 1; at all other moments, calves were group-housed in pens $(5 / 6$ calves per pen), but calves were still individually examined using protocol 2, which was based on the Welfare Quality Protocol for veal calves (Brscic et al., 2012; Supplemental Table S2, https://doi.org/10.6084/m9 .figshare.17024522.v1, van Reenen, 2021). In contrast to protocol 1, protocol 2 did not require physical interaction of the human observer with individual animals (i.e., to examine the clinical condition of the navel and the skin elasticity of calves) and was, therefore, more suitable and feasible for recording the clinical condition of group-housed growing veal calves. Notably, during the clinical assessment using protocol 2 the observer remained outside the pen at all times. Protocol 2 was also consistent with the health assessment performed in one of our previous studies (Marcato et al., 2020). Again, similar to the health assessments on the dairy farm, we restricted ourselves to weekly observations with the aim to reveal any differences in health status between treatment groups on a cross-sectional basis. Presence of loose or liquid manure in group-housed calves could only be observed by inspecting the floor and could, therefore, not be reliably associated with an individual calf. Hence, loose and liquid manure was not part of protocol 2. Health assessments of calves at the dairy and veal farms were performed by in total 5 different observers. These observers were thoroughly trained before the experiment, theoretically as well as practically (on-farm), and interobserver reliability was tested at the end of the training period (k-coefficient $=98 \%$ obtained from a cumulative score reported by the 2 observers). Assessors were trained to identify the most common health problems in veal calves and they performed various rounds where they compared their health score. When a consistently high k-coefficient was obtained, then both observers were judged ready to perform the health assessment in the current experiment.

\section{Antibiotics and Other Medical Treatments}

At both dairy and veal farms, the use of antibiotics and other medical treatments was recorded at individual calf level. Information on individual treatments included the following data: (1) whether or not a calf was 
treated with antibiotics or other medicines (this latter category referred to products other than antibiotics, such as antiinflammatories, multivitamins, and anticoccidial drugs); (2) whether single or repeated antibiotic/ medical treatments were applied; and (3) age at which treatments were applied. Herd treatments (applied on all calves, via the milk) were also recorded during the rearing period at the veal farm, as well as the age at which the herd treatments were applied and the type of medication that was used.

\section{$B W, A D G$, and Carcass Weight}

All calves at the dairy farms were weighed on an portable scale (model MW/VHD300/D from Breinler International B.V.) on a weekly basis until $1 \mathrm{~d}$ before transport. The scale was always calibrated before use. Subsequently, the BW of each calf was recorded upon arrival at the veal farm (model HMV1, Henk Maas Weegschalen B.V.), and finally, carcass weight was obtained at slaughter. The ADG at the dairy farm was calculated on a weekly basis.

\section{Calf and Cow Characteristics}

Characteristics of calves and their dams were recorded at the dairy farm. With regard to calves, BW at birth, breed, and sex were recorded; with regard to dam characteristics, parity and ease of birth of calves were recorded. Ease of birth was recorded as a binary response, where a score $=0$ indicated a calving process without the assistance of the farmer, and a score $=1$ indicated that assistance of the farmer was required during the calving process.

\section{Mortality Risk at the Dairy Farm and at the Veal Farm}

Mortality risk was calculated separately for calves transported either at 14 or $28 \mathrm{~d}$ of age, as well as for different breeds and sexes of calves. Total mortality risk at the dairy farm was calculated as the sum of calves intended for veal production that died or were euthanized by a veterinarian before being transported to a veal farm, divided by the total number of surplus calves. Total mortality risk at the veal farm was calculated as the sum of the numbers of calves that died, were euthanized by a veterinarian for health reasons, or were prematurely slaughtered because of poor performance (i.e., did not successfully complete the rearing period at the veal farm) divided by the total number of calves present upon arrival at the veal farm.

\section{Data Processing and Statistical Analyses}

Before the statistical analyses, the distribution of calves across (experimental) factors was checked. Within each transport age treatment group, the different levels of other factors including sex, parity of dam, ease of birth, and breed were sufficiently (almost equally) represented (see Supplemental Table S3, https://doi.org/10.6084/m9.figshare.17024522.v1, van Reenen, 2021) to allow for an unbiased estimation of all main effects and, if present, their interactions. Continuous response variables (e.g., BW, ADG, and carcass weight) were analyzed with a linear mixed model (LMM). Components of variance were estimated with REML, employing the MIXED procedure from SAS 9.4 (SAS Institute Inc.). Residuals were always checked for normality and homogeneity of variance, and variables were log-transformed when needed. Response variables about health of calves were expressed as binary variables [also rectal temperature $(0=$ calves with temperature $<39.5^{\circ} \mathrm{C} ; 1=$ calves with temperature $\geq 39.5^{\circ} \mathrm{C}$; Garcia et al., 2015) to investigate the prevalence of fever] and were analyzed with a generalized linear mixed model (GLMM), comprising a logit link function and the Bernoulli variance as an "error" variance. Inference was by penalized quasi-likelihood (PQL, which is equivalent to the use of pseudo-likelihood), employing SAS procedure GLIMMIX. Approximate $F$-tests (Kenward and Roger, 1997) were used for fixed effects. Subsequent pairwise comparisons were done with Fisher's least significant difference method. Two-way interactions between fixed effects were included in all models, and interactions were considered not significant when $P>0.05$. When the fixed part of the model included both quantitative covariates and qualitative factors, interactions between covariates and factors were tested to see whether the assumption of equal slopes was tenable. In all analyses, effects with $P \leq 0.05$ were considered significant. Table 1 shows all the details related to the models used for the analyses.

Mortality risks were too low to allow for a parametric analysis as described above. Therefore, the nonparametric Wilcoxon signed rank test (two-tailed) was performed to test for differences in mortality risk at both the dairy farm and the veal farm between calves transported at either 14 or $28 \mathrm{~d}$ of age and for different breeds and sexes of calves. For each dairy farm and veal farm, respectively, 2 matched (dependent) observations were available, that is, the mortality risks among calves transported at 14 and $28 \mathrm{~d}$, or among calves of Holstein Friesian and crossbreed, or among male and female calves, respectively. Effects with $P \leq 0.05$ were considered significant. 
Marcato et al.: EFFECTS OF TRANSPORT AGE ON HEALTH OF VEAL CALVES

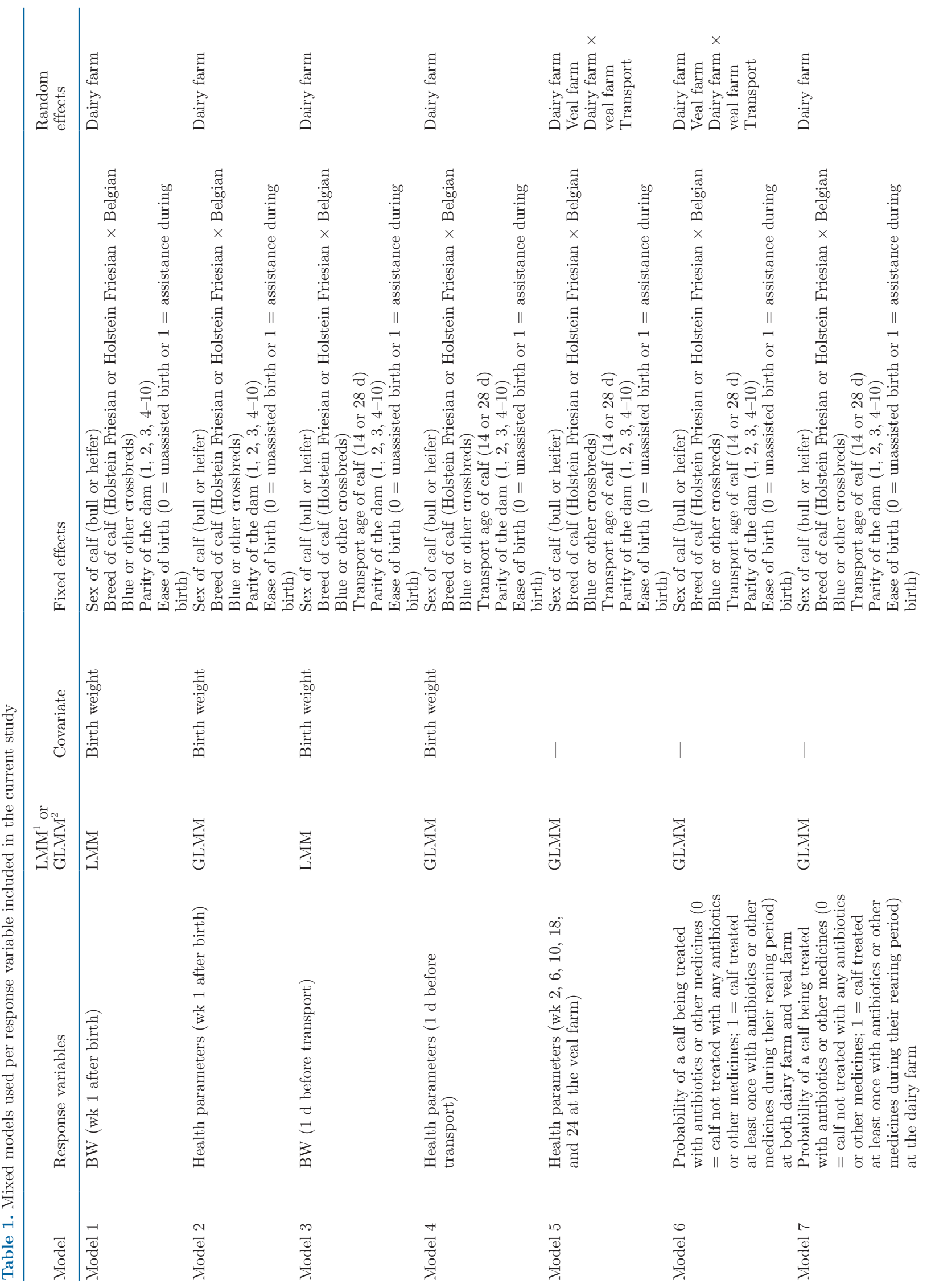


Marcato et al.: EFFECTS OF TRANSPORT AGE ON HEALTH OF VEAL CALVES

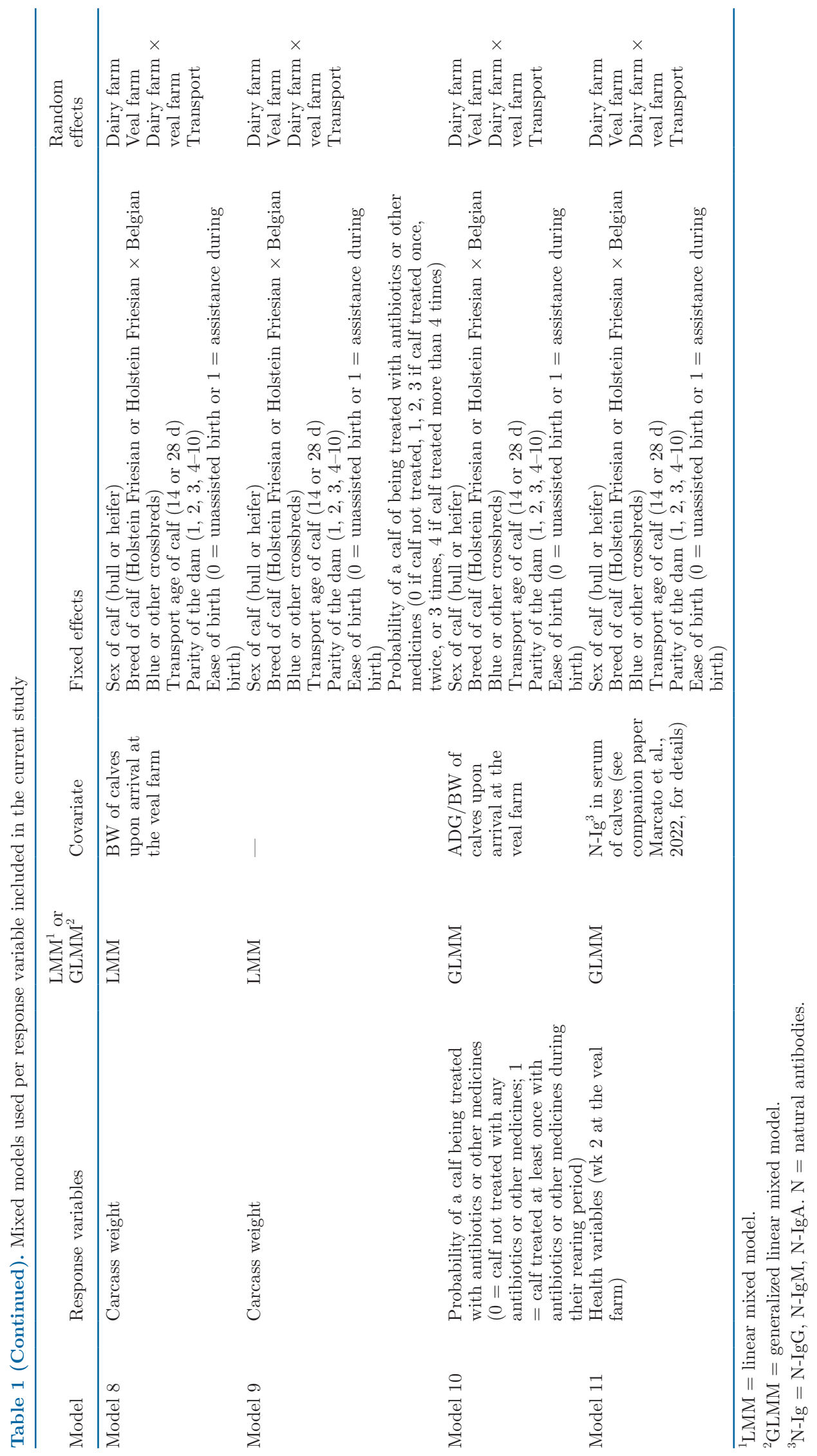




\section{RESULTS}

\section{Effects of Transport Age}

One day before transport, the percentage of calves with loose or liquid manure was greater $(\Delta=16.6 \%)$ in calves transported at $14 \mathrm{~d}$ compared with calves transported at $28 \mathrm{~d}(P<0.01$; Table 2$)$. The percentage of calves with an impaired skin elasticity (score 1 and 2; $\Delta=6 \%$ ) was greater in the 14-d group compared with the 28-d group, whereas BW at transport was lower $(\Delta$ $=-11.8 \mathrm{~kg}$ ) in calves transported at $14 \mathrm{~d}$ than calves transported at $28 \mathrm{~d}(P<0.05$; Table 2$)$. Transport age did not affect health parameters assessed 2 wk after arrival at the veal farm (Table 3). Beyond wk 2 , prevalences of clinical signs of respiratory problems were generally quite low (Figure 1), and prevalences of other clinical health problems were $<10 \%$. The percentage of calves that received at least one individual medical treatment other than antibiotics at the veal farm was greater $(\Delta=5.4 \%)$ in calves transported at $14 \mathrm{~d}$ compared with calves transported at $28 \mathrm{~d}(P=$ 0.02; Table 4). In contrast, at the dairy farm of origin, this percentage was greater $(\Delta=5.4 \%)$ in calves transported at $28 \mathrm{~d}$ in comparison with calves transported at $14 \mathrm{~d}(P=0.03$; Table 4$)$. At the dairy farm, the number of calves individually treated with antibiotics tended to be greater in the 28 - $\mathrm{d}$ treatment group relative to the 14-d treatment group $(P=0.08$; Table 4$)$. At the veal farm there were no differences between the 2 transport age groups in the prevalence of calves that were individually treated with antibiotics (Table 4). In the current experiment, dairy farmers provided calves with treatments other than antibiotics (such as antiprotozoal solutions, antispasmodics, and antiinflammatory drugs) to reduce diarrhea. At the veal farm the main purpose of using treatments other than antibiotics (mainly antiinflammatories) was to reduce respiratory problems. Calves transported at $14 \mathrm{~d}$ had a lower carcass weight at slaughter $(\Delta=-14.8 \mathrm{~kg})$ compared with calves transported at $28 \mathrm{~d}(P<0.01$; Table 5$)$.

\section{Effects of Calf Sex}

Body weight measured in wk 1 after birth and a day before transport was greater $(\Delta=1.8 \mathrm{~kg}$ and $\Delta=5.8$ $\mathrm{kg}$, respectively) in bull calves compared with female calves (both $P<0.01$; Table 2 and Table 6). Calf sex did not affect health parameters assessed at the dairy farm (wk 1 and $1 \mathrm{~d}$ before transport), but bull calves showed more signs of navel inflammation $(\Delta=7.3 \%)$ compared with female calves in wk 2 posttransport $(P$ $=0.02$; Table 3). Beyond wk 6 posttransport, sex did not affect health. In terms of individual antibiotic and

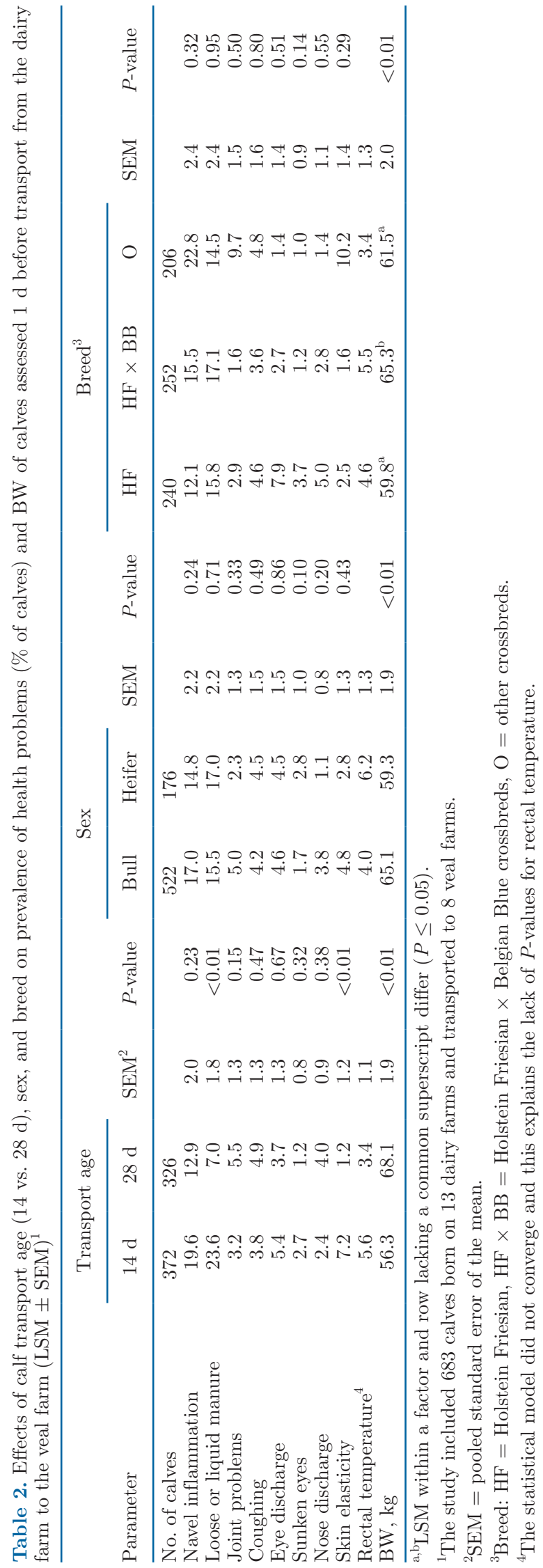




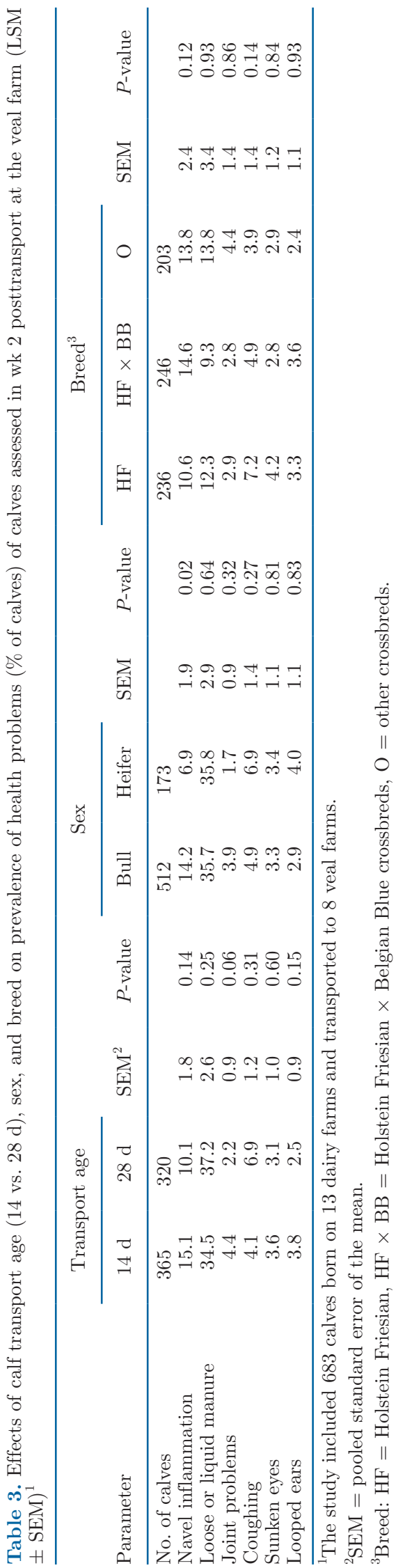

other medical treatments, no significant differences were found between bull and females calves (Table 4). Carcass weights at slaughter were greater $(\Delta=16.8$ $\mathrm{kg})$ for bull calves compared with female calves $(P<$ 0.01 ; Table 5).

\section{Effects of Calf Breed}

Belgian Blue crossbred calves had a greater BW in wk 1 after birth $(\Delta=1.5 \mathrm{~kg}$ on average) and a day before transport ( $\Delta=4.6 \mathrm{~kg}$ on average) compared with Holstein Friesian calves and other crossbreds (both $P$ $<0.01$; Tables 2 and 6 ). Breed did not affect clinical health parameters assessed at the dairy and veal farms. Total use of individual antibiotic and other medicine treatments in calves at the dairy and veal farms was greater in other crossbreds calves $(\Delta=17.3 \%$ and $\Delta=$ $20.2 \%$ on average, respectively) compared with Holstein Friesian calves and Belgian Blue crossbreds (both $P<$ 0.05; Table 4). The prevalence of calves individually treated with antibiotics and other medicines only at the veal farm was also greater in other crossbred calves ( $\Delta=13.6 \%$ and $\Delta=13.4 \%$ on average, respectively) compared with Holstein Friesian calves and Belgian Blue crossbreds (both $P=0.04$; Table 4). Breed had a significant influence on carcass weight at slaughter $(P$ $<0.05$. Table 5). Belgian Blue crossbreds had a greater carcass weight compared with other crossbreds $(\Delta=$

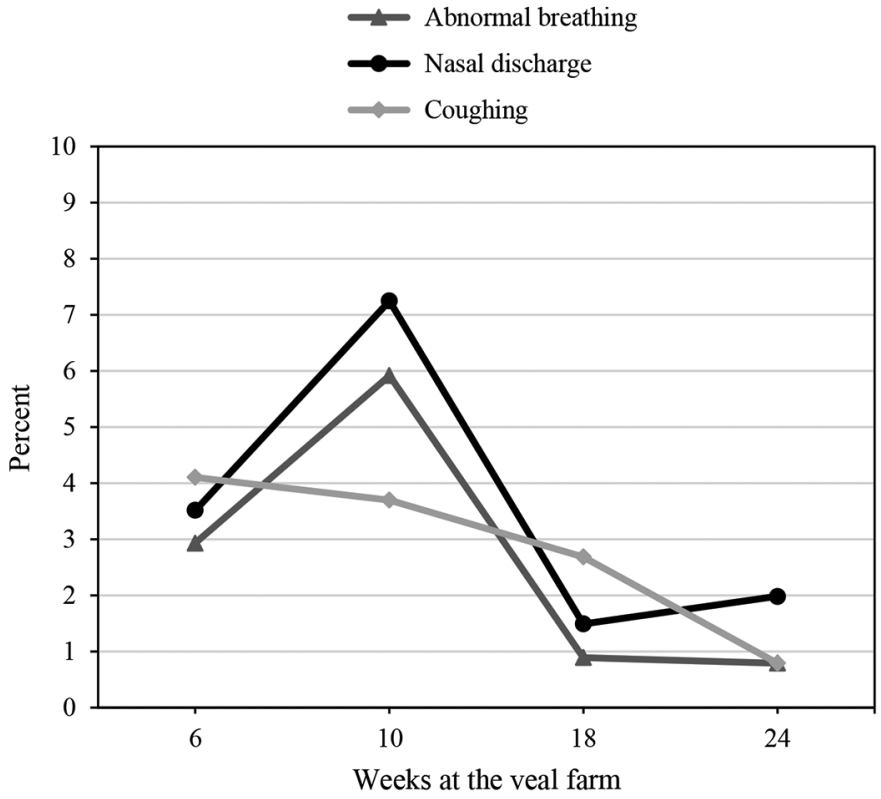

Figure 1. Prevalence of abnormal breathing, nasal discharge, and coughing in veal calves in wk $6,10,18$, and 24 at the veal farm (expressed as proportion of calves). Calves $(\mathrm{n}=683)$ were transported at 14 or $28 \mathrm{~d}$ of age from 13 dairy farms to 8 veal farms. 
Marcato et al.: EFFECTS OF TRANSPORT AGE ON HEALTH OF VEAL CALVES
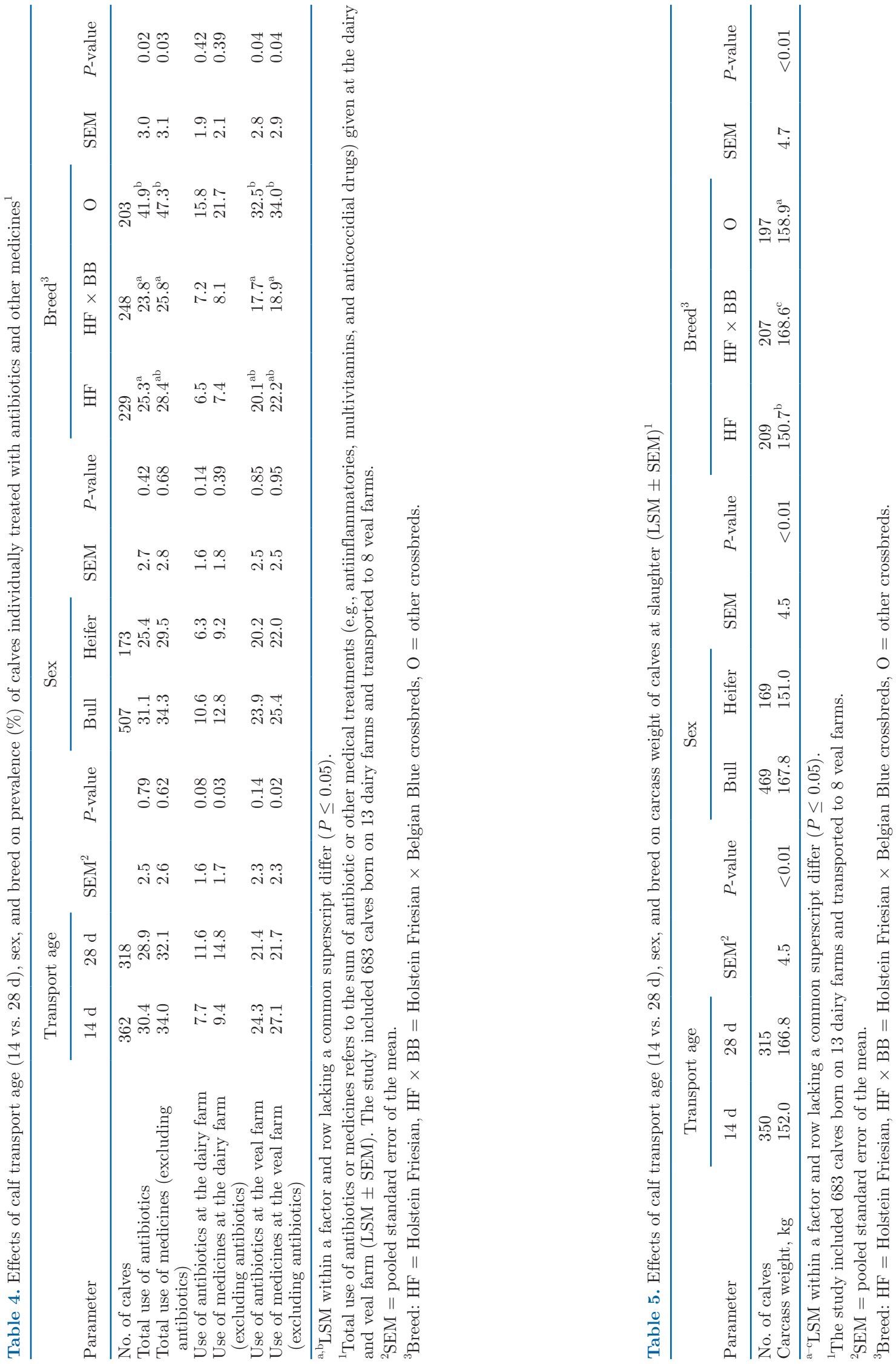


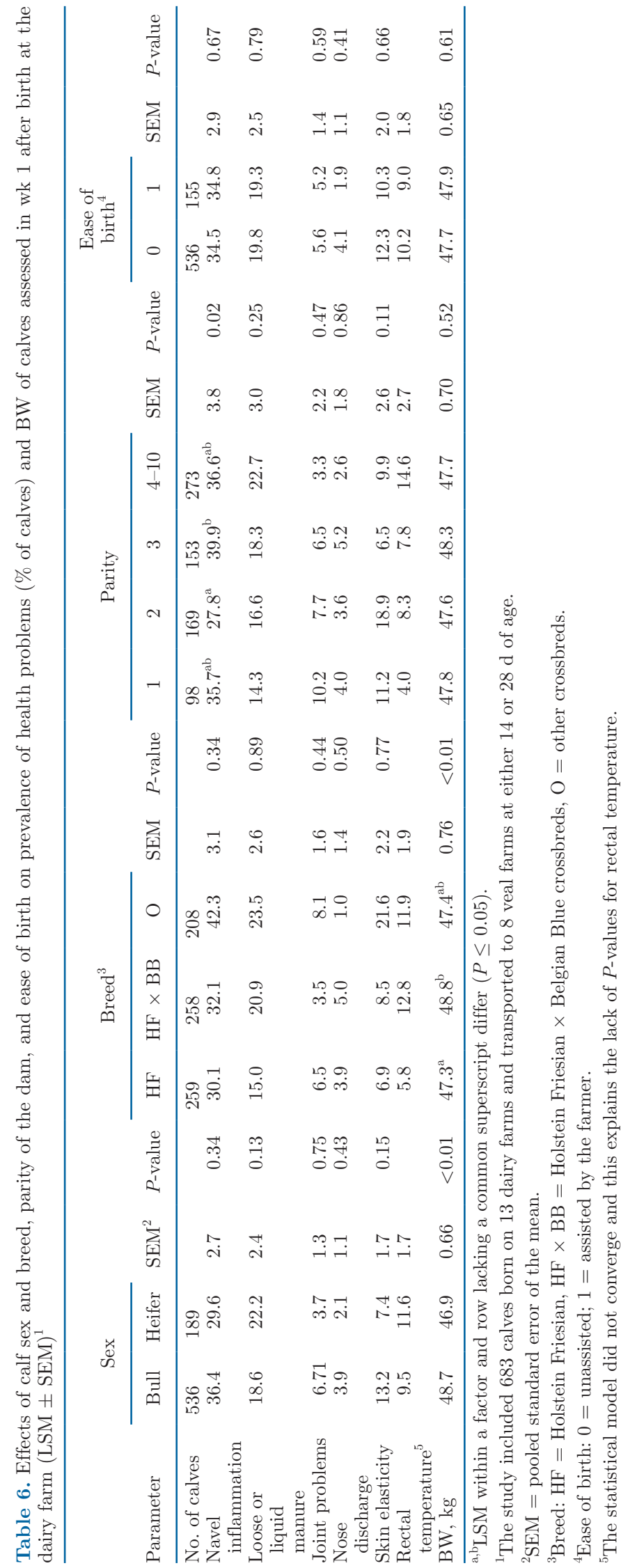

$9.7 \mathrm{~kg})$ and Holstein Friesian calves $(\Delta=17.9 \mathrm{~kg}, P$ $<0.01)$.

\section{Effects of Parity}

In wk 1 after birth, calves born from second-parity cows showed less signs of navel inflammation than calves from third-parity cows $(\Delta=-12.1 \%, P=0.02$; Table 6 ) and other parity classes. One day before transport, BW of calves born from first-parity cows $(\Delta=-4.7$ $\mathrm{kg}$ on average) was lower compared with calves born from greater parity cows $(P<0.01$; Table 7$)$. Parity of the dam did not affect health parameters assessed at the veal farm, or the individual use of antibiotics and other medical treatments (Table 8). In addition, carcass weights at slaughter were not affected by parity of the dam (Table 9).

\section{Effects of Ease of Birth}

Calves born with assistance of the farmer had a greater BW a day before transport $(\Delta=2.5 \mathrm{~kg} ; P<$ 0.01 ; Table 7 ) than calves born without assistance. Ease of birth did not affect any health parameters assessed at the dairy and veal farms and did not have an influence on individual use of antibiotics and other medical treatments (Tables 6, 8, and 10). Carcass weights were also not affected by ease of birth (Table 9 ).

\section{Herd Treatments with Antibiotics and Medicines}

In addition to individual treatments, calves were subjected to an average of 4.4 herd treatments with antibiotics and 3.9 herd treatments with other medicines at the veal farm. The antibiotic treatments were provided via the milk for an average of 10 feedings over $5 \mathrm{~d}$ per treatment. The majority of herd treatments was applied in the first $2 \mathrm{wk}$ posttransport and that applied to all veal farms. The most common antibiotics administered included tetracycline and oxytetracycline. The second most frequently administered antibiotics involved macrolides, such as tilmicosin.

\section{Relationships Between Individual Use of Antibiotics or Other Medicines and Carcass Weight}

Calves that received 3 or more individual treatments with antibiotics or other medicines had a lower carcass weight at slaughter $(\Delta=-13.6 \mathrm{~kg}$ on average for antibiotics and $\Delta=15.0 \mathrm{~kg}$ on average for other medicines, respectively) compared with calves treated once or twice $(P<0.01 ;$ Table 11). Additionally, calves not treated at all had a greater carcass weight compared with calves individually treated at least once with an- 
Table 7 . Effects of parity of the dam and ease of birth on prevalence of health problems (\% of calves), BW, and rectal temperature of calves assessed $1 \mathrm{~d}$ before transport to the veal farm $(\mathrm{LSM} \pm \mathrm{SEM})^{1}$

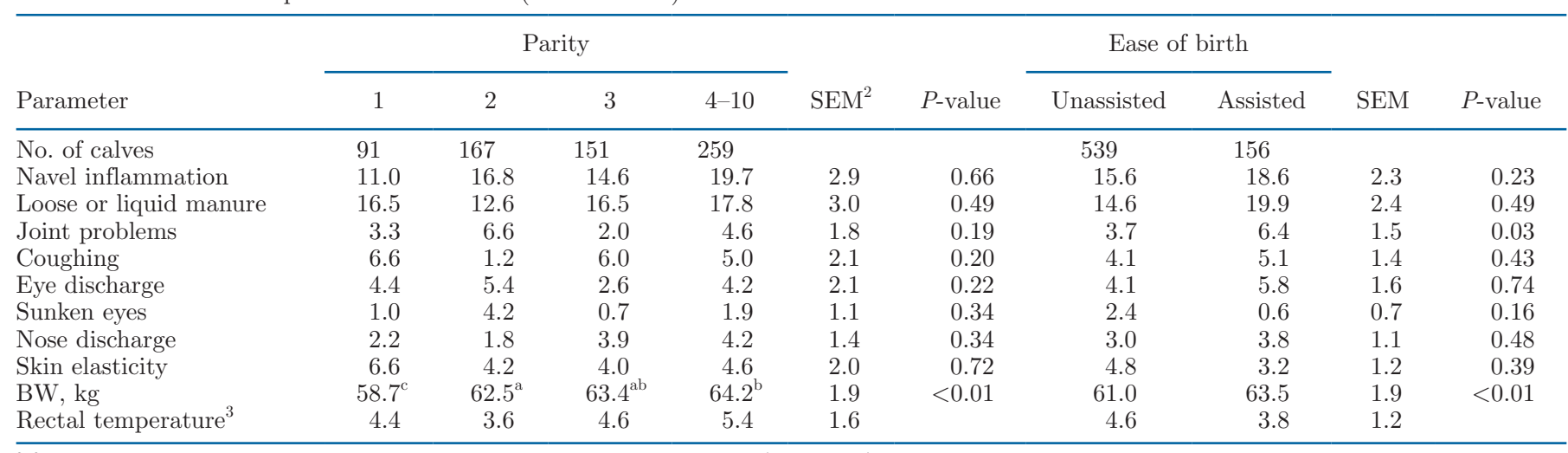

${ }^{\mathrm{a}-\mathrm{C}} \mathrm{LSM}$ within a factor and row lacking a common superscript differ $(P \leq 0.05)$.

${ }^{1}$ Calves $(\mathrm{n}=683)$ were transported at 14 or $28 \mathrm{~d}$ of age from 13 dairy farms to 8 veal farms.

${ }^{2} \mathrm{SEM}=$ pooled standard error of the mean.

${ }^{3}$ The statistical model did not converge and this explains the lack of $P$-values for rectal temperature.

tibiotics $(\Delta=19.6 \mathrm{~kg}$ on average $)$ and other medicines ( $\Delta=16.1 \mathrm{~kg}$ on average). The results on individual treatments with antibiotics and other medicines at the veal farm were also in line with the results on total use at both dairy and veal farms (Table 11).

\section{Relationships Between BW Upon Arrival or ADG at the Dairy Farm and Later Performance}

The relationship between use of antibiotics or other medicines and BW upon arrival was not significant. The relationship between use of antibiotics or other medicines and ADG at the dairy farm was also not significant. Body weight upon arrival and ADG at the dairy farm were both positively associated with carcass weight at slaughter $(\beta=0.228, \mathrm{SE}=0.05$, and $\beta=$
$15.1, \mathrm{SE}=3.12$, respectively; $P<0.01$ ). These regression coefficients were obtained from regression models without the interaction term, that is, on the assumption of homogeneity of regression slopes (slopes are parallel for different ages of transport, parity groups, sexes, and breeds). The interaction between BW upon arrival and the fixed effect of transport age was significant $(P<$ 0.01). Thus, slopes of the covariable BW upon arrival were not the same for the 2 transport age groups. The effect of BW upon arrival on carcass weight was much greater for calves transported at $28 \mathrm{~d}$ of age $(\beta=0.85$, $\mathrm{SE}=0.13)$ than for calves transported at $14 \mathrm{~d}$ of age $(\beta$ $=0.13, \mathrm{SE}=0.05)$. At the same time, after introduction of BW upon arrival as a covariable in the model, the effect of transport age on carcass weight remained significant $(P<0.01)$. Carcass weights corrected for

Table 8. Effects of parity and ease of birth on prevalence (\% of calves) of individual treatments with antibiotics and other medicines ${ }^{1}$

\begin{tabular}{|c|c|c|c|c|c|c|c|c|c|c|}
\hline Parameter & \multicolumn{4}{|c|}{ Parity } & $\mathrm{SEM}^{2}$ & $P$-value & \multicolumn{2}{|c|}{ Ease of birth } & SEM & $P$-value \\
\hline No. of calves & 88 & 166 & 146 & 254 & & & 526 & 151 & & \\
\hline Total use of medicines & 42.0 & 36.7 & 28.8 & 30.7 & 3.9 & 0.40 & 32.1 & 37.1 & 3.0 & 0.55 \\
\hline $\begin{array}{l}\text { Use of antibiotics at the dairy } \\
\text { farm }\end{array}$ & 12.5 & 12.6 & 7.5 & 7.9 & 2.5 & 0.60 & 9.3 & 10.6 & 1.9 & 0.95 \\
\hline $\begin{array}{l}\text { Use of antibiotics at the veal } \\
\text { farm }\end{array}$ & 31.8 & 21.7 & 18.5 & 23.6 & 3.5 & 0.47 & 21.9 & 27.1 & 2.7 & 0.67 \\
\hline $\begin{array}{l}\text { Use of medicines at the veal } \\
\text { farm }\end{array}$ & 32.9 & 22.9 & 22.6 & 24.4 & 3.6 & 0.59 & 23.4 & 29.1 & 2.8 & 0.55 \\
\hline
\end{tabular}

${ }^{1}$ Total use of antibiotics or medicines refers to the sum of antibiotic or medical treatments given at the dairy and veal farm (LSM \pm SEM). The study included 683 calves born on 13 dairy farms and transported to 8 veal farms at either 14 or $28 \mathrm{~d}$ of age.

${ }^{2} \mathrm{SEM}=$ pooled standard error of the mean. 
Table 9. Effects of parity of the dam and ease of birth on carcass weight of calves at slaughter (LSM \pm SEM) ${ }^{1}$

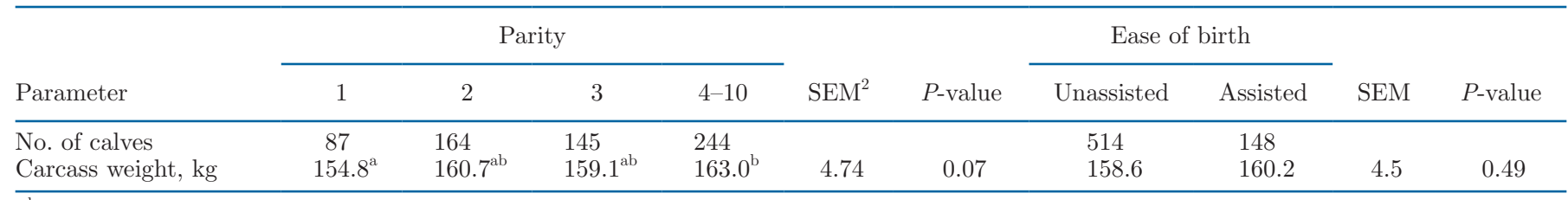

$\overline{\mathrm{a}, \mathrm{b}} \mathrm{LSM}$ within a factor and row lacking a common superscript differ $(P \leq 0.05)$.

${ }^{1}$ The study included 683 calves born on 13 dairy farms and transported to 8 veal farms at either 14 or $28 \mathrm{~d}$ of age.

${ }^{2} \mathrm{SEM}=$ pooled standard error of the mean.

BW upon arrival of calves transported at either 14 or $28 \mathrm{~d}$ of age were $152.9 \pm 4.6$ and $165.7 \pm 4.7 \mathrm{~kg}$, respectively (LSM \pm SEM).

\section{Mortality Risk at the Dairy Farm and at the Veal Farm}

Mortality risk at the dairy farm was not significantly different between calves in the $14 \mathrm{~d}$ and in the $28 \mathrm{~d}$ group ( $2.7 \%$ vs. $4.3 \%$, respectively; $P=0.412$, Wilcoxon signed rank test). In contrast, mortality at the veal farm was greater in calves transported at $14 \mathrm{~d}$ of age compared with calves transported at $28 \mathrm{~d}$ of age ( $5.9 \%$ vs. $2.8 \%$, respectively, $P=0.03$, Wilcoxon signed rank test). Notably, on 5 out of the total of 8 veal farms involved in the present experiment no mortality occurred during the entire rearing period among calves that were transported at $28 \mathrm{~d}$ of age, whereas among calves transported at $14 \mathrm{~d}$ of age this only held for 1 veal farm. No significant differences in mortality risk were found between different breeds or sexes of calves.

\section{DISCUSSION}

\section{Effects of Transport Age}

To the best of our knowledge, the current study is the first to systematically examine and demonstrate effects of different transport ages of calves from the dairy farm to the veal farm on health and performance of veal calves. When calves in the Netherlands are usually transported to the veal farm (i.e., around $14 \mathrm{~d}$ of age) the animals are in the so called "immune gap period" (Hulbert and Moisá, 2016), in which maternal antibodies decrease, while the calves' own adaptive immune system is still immature (Hulbert and Moisá, 2016). Results of the companion paper (Marcato et al., 2022) demonstrated that the "immune gap" exists in both age groups (14 and $28 \mathrm{~d}$ ) at the moment of transport, but the developmental stage of the adaptive immune system appears to be more advanced in calves transported at $28 \mathrm{~d}$ instead of $14 \mathrm{~d}$. To try to understand whether or not a possible difference in adaptive immunity between transport age groups is reflected in differences in the health status of calves, the current study investigated the effects of transport age on various measures of robustness of calves at the veal farm. One day before transport, calves transported at $14 \mathrm{~d}$ of age had a greater prevalence of loose or liquid manure and more signs of dehydration (as indicated by skin elasticity) compared with calves transported at $28 \mathrm{~d}$ of age. Calves transported at $14 \mathrm{~d}$ also had a lower BW at transport and upon arrival at the veal farm compared with calves transported at $28 \mathrm{~d}$. These pre-transport signs shown by 14-d calves might be all linked to a lower robustness of calves upon arrival at the veal farm. Smith (2009) indicated that diarrhea might be responsible for creating dehydration, possibly resulting in a greater mortality at the veal farm (Berchtold, 2009;

Table 10. Effects of parity of the dam and ease of birth on prevalence of health problems (\% of calves) observed in wk 2 posttransport at the veal farm $(\mathrm{LSM} \pm \mathrm{SEM})^{1}$

\begin{tabular}{|c|c|c|c|c|c|c|c|c|c|c|}
\hline Parameter & \multicolumn{4}{|c|}{ Parity } & $\mathrm{SEM}^{2}$ & $P$-value & \multicolumn{2}{|c|}{ Ease of birth } & SEM & $P$-value \\
\hline Navel inflammation & 13.3 & 15.1 & 14.1 & 11.5 & 2.8 & 0.77 & 13.2 & 12.4 & 2.1 & 0.34 \\
\hline Loose or liquid manure & 34.4 & 43.4 & 31.5 & 34.5 & 3.9 & 0.15 & 35.0 & 37.9 & 3.0 & 0.55 \\
\hline Joint problems & 5.5 & 2.4 & 3.3 & 3.2 & 1.6 & 0.29 & 3.4 & 2.6 & 1.0 & 0.16 \\
\hline Coughing & 4.4 & 7.8 & 3.3 & 5.5 & 1.8 & 0.28 & 5.7 & 4.6 & 1.4 & 0.49 \\
\hline
\end{tabular}

${ }^{1}$ Calves $(\mathrm{n}=683)$ were transported at 14 or $28 \mathrm{~d}$ of age from 13 dairy farms to 8 veal farms.

${ }^{2} \mathrm{SEM}=$ pooled standard error of the mean. 
Table 11. Effect of the number of individual treatments with antibiotics or other medicines on carcass weight of veal calves (LSM \pm SEM) ${ }^{1}$

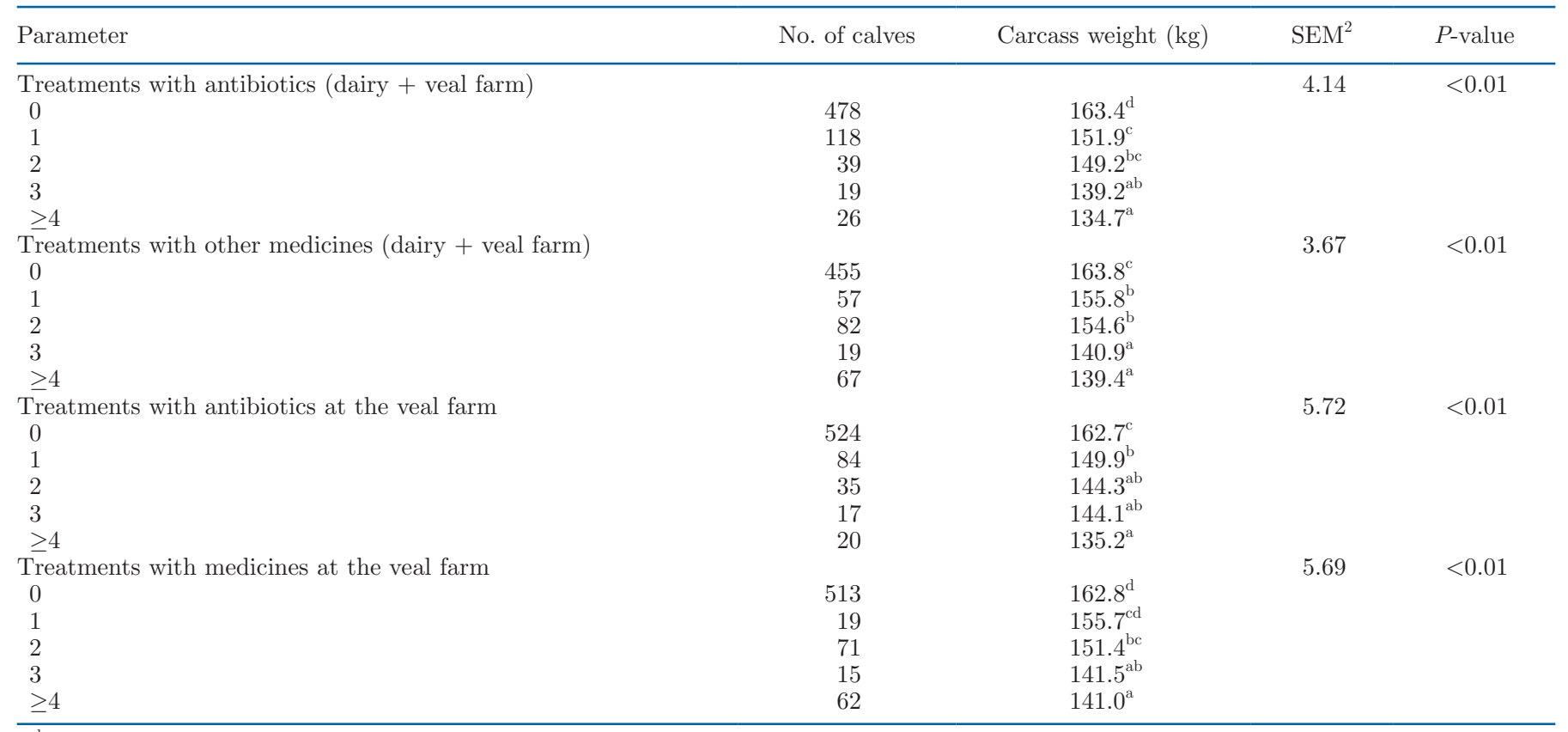

${ }^{\mathrm{a}-\mathrm{d}}$ LSM within a factor and row lacking a common superscript differ $(P \leq 0.05)$.

${ }^{1}$ The current study included 683 calves born on 13 dairy farms and transported to 8 veal farms at either 14 or $28 \mathrm{~d}$ of age.

${ }^{2} \mathrm{SEM}=$ pooled standard error of the mean.

Renaud et al., 2018). However, this latter study did not find a relationship between fecal score and dehydration; thus, they could not conclude that diarrhea is associated with dehydration. Moreover, this experiment was not conducted with calves transported at different ages, so potential relationships between transport age, diarrhea, dehydration, and mortality could not be established.

Health checks were performed on a weekly basis during the current experiment and this approach was useful to reveal any differences in health status between treatment groups on a cross-sectional basis, similar to our previous studies (Brscic et al., 2012; Marcato et al., 2020). However, the use of weekly health checks might be a limitation for not taking into account the daily variation of health problems in calves. In the present experiment, in spite of a clear health difference between transport age groups $1 \mathrm{~d}$ before transport, no effects of transport age on measures of clinical health at the veal farm were found. In addition, the prevalences of health problems of calves entering the veal farm were in line with previous studies on veal calves (e.g., Marcato et al., 2020). In the second week upon arrival, prevalences of loose and liquid manure were not only similar between transport age groups, but also much greater (over 35\% on average) than at the dairy farm $1 \mathrm{~d}$ before transport (15\% on average). Apparently, all calves regardless of transport age had difficulty coping with the transition from the dairy farm to the veal farm, in adjusting their digestive system. Since it was not possible to distinguish between infectious or feed-related loose or liquid manure, it remains unknown the extent to which exposure to pathogens or, for example, a change in dietary conditions was the defining factor here. The prevalences of loose or liquid manure observed at the veal farm are in line with previous studies in veal calves (Wilson et al., 2000; Marcato et al., 2020). In the study of Marcato et al. (2020), the prevalence of this condition also sharply increased in the first $3 \mathrm{wk}$ posttransport (from $5 \%$ upon arrival at the veal farm to $39 \%$ in wk 3). Beyond wk 2 , prevalences of clinical signs of respiratory problems were generally quite low $(<5 \%$ at the beginning of the rearing period, and always $<10 \%$ ), which is in contrast with other studies (e.g., Pardon et al., 2015). The prevalences of all other clinical parameters were even lower $(<5 \%)$. In view of the high number of herd treatments with antibiotics applied on the veal farms that participated in the current experiment (i.e., on average 4.4 herd treatments per farm), it seems likely that bacterial infections were largely suppressed, which may also have masked differences in clinical consequences between treatment groups. Another recent paper (Buss et al., 2021) has also demonstrated that provision of neomycin as oral group treatment via milk replacer resulted in suppression of diarrhea compared with calves receiving unmedicated milk replacer. Interestingly, despite an 
overall high level of antimicrobial use in this study, in comparison with calves transported to the veal farm at $28 \mathrm{~d}$ of age, a greater proportion of calves transported at $14 \mathrm{~d}$ of age received individual medical treatments other than antibiotics. This could be interpreted as an indication of lower vigor in calves transported at $14 \mathrm{~d}$ of age compared with the calves transported at $28 \mathrm{~d}$ of age. Two additional findings from the current study seem to support this idea. First, even after correcting carcass weight for BW upon arrival, the effect of age of transport on carcass weight remained significant. This suggests that the ultimate difference in carcass weight between transport age groups at the end of the rearing period was not just the consequence of an age-related BW difference that existed at the time of arrival at the veal farm, but that differences between transport age groups became larger during rearing. This is supported by the slope of the relationship between carcass weight and BW upon arrival at the veal farm, which was considerably steeper for calves transported at $28 \mathrm{~d}$ of age than for calves transported at $14 \mathrm{~d}$ of age. It might be that older calves grew faster because of a greater feed intake. However, further research would be necessary to characterize growth curves of calves from arrival at the veal farm until slaughter in more detail, and to examine feed intake and feed efficiency as a function of calf age. Second, the mortality rate of calves transported to the veal farm at $14 \mathrm{~d}$ of age was greater than the mortality risk of calves transported at $28 \mathrm{~d}$. Since mortality risk is generally considered the ultimate measure of robustness (Marcato et al., 2018; de Almeida et al., 2019), it can be proposed that transportation of calves from the dairy farm to the veal farm at 28 rather than $14 \mathrm{~d}$ of age might contribute to a greater robustness of the animals. A more advanced adaptive immune system in calves transported at $28 \mathrm{~d}$ relative to animals transported at $14 \mathrm{~d}$, among other things reflected in differences between age groups in immunoglobulin isotypes and various immune cell counts (Marcato et al., 2022), might be one of the influencing factors behind this difference. Despite the potential relevance of all these findings, keeping calves longer on a dairy farm might also be suboptimal and further research is needed on this topic. In fact, as suggested in the companion paper (Marcato et al., 2022), calves kept longer on a dairy farm may have not developed a proper environmentspecific adaptive immunity, which is important when calves are moved to a new environment such as the veal farm. Moreover, keeping calves longer on the dairy farm may result in a shift of diseases and health problems back to the dairy farms of origin and this might potentially lead to an increase in the use of medicines and, perhaps, mortality at the dairy farm. Since, in comparison with veal farmers, dairy farmers are not yet specialized in keeping surplus calves longer than approximately $2 \mathrm{wk}$, this may make calf rearing on the dairy farm more demanding. The current finding that the prevalences of animals treated with antibiotics and medicines other than antibiotics at the dairy farm were greater in calves transported at $28 \mathrm{~d}$ of age in comparison with calves transported at $14 \mathrm{~d}$ of age might be an indication of this.

\section{Effects of Breed}

As reported by Diana et al. (2021), breed is an important factor with a strong effect on performance traits, antimicrobial use, and risk of mortality in beef cattle. Beef breeds with a greater BW at the beginning of the rearing period had a lower likelihood to be treated with antimicrobials. In our study, Belgian Blue $\times$ Holstein Friesian calves were heavier upon arrival at the veal farm compared with other crossbreds and Holstein Friesian calves. This can be attributed to the genetics of Belgian Blue, which is a breed with exaggerated muscular growth (Fiems et al., 2013), rather than a characteristic associated with improved robustness. Total use of antibiotics was greater in other crossbreds compared with both Holstein Friesian and Belgian Blue $\times$ Holstein Friesian calves. These results are in contrast to the idea that crossbreds are more robust than pure breeds (Clasen et al., 2017, 2019), and they indicate that there might be a difference in robustness among different types of crossbreds. Moreover, previous studies reported that double muscled breeds, such as Belgian Blue, may even have an impaired immunity due to their lower amount of body fat, which may affect their susceptibility to diseases and performance (Fiems, 2012; Pardon et al., 2012). In the current study, differences in clinical health status among breeds were not present. However, our study showed that the use of antibiotics and other medicines at the veal farm was greater in other crossbreds compared with Belgian Blue $\times$ Holstein Friesian calves. These results might be an indication that crossbreds other than Belgian Blue $x$ Holstein Friesian calves are less robust, but this would need confirmation in future research.

\section{Effects of Sex}

The sex of the calves is another factor that is not extensively investigated in veal calves and might affect their production traits and robustness. Previous studies showed that, already in early life, sex-related differences in the immune system and sex hormone milieu in humans and animals are contributing factors for a greater disease susceptibility and mortality of males compared with females (Baxter et al., 2012; Zarulli et 
al., 2018; Pradhan and Olsson, 2020). In support of these findings, the prevalence of navel inflammation in wk 2 posttransport was greater in bull calves compared with heifer calves. However, sex did not affect mortality risk at the veal farm. The high prevalence of inflamed navels in bull calves upon arrival at the veal farm is a common problem in the veal industry (Wilson et al., 2000; Renaud et al., 2018). Wilson et al. (2000) showed that the percentages of bull calves with unacceptable navel scores (scores 1 and 2) were $32 \%$ and $23.7 \%$ upon arrival and $28 \mathrm{~d}$ posttransport, respectively. Moreover, Renaud et al. (2018) showed that bull calves with enlarged and inflamed navels (score 3) upon arrival at the veal farm are at a greater risk for early $(<21 \mathrm{~d}$; odds ratio $=2.4)$ and late $(>21 \mathrm{~d}$; odds ratio $=1.8)$ mortality than the reference category with navel score 0 or 1. Eventually this infection can spread to other parts of the body and affect multiple organs. To prevent this condition and the corresponding use of antibiotic treatments, hygiene should be monitored and the navel of all bull and surplus female calves should be carefully dipped into disinfecting solutions after birth at the dairy farms of origin (Mee, 2008; Renaud et al., 2018).

\section{Effects of Parity}

The current study as well as results of the companion paper (Marcato et al., 2022) showed that parity affected calf performance not only around birth, but also in the longer term. In fact, calves born from first-parity cows had a lower BW in wk 1 after birth and $1 \mathrm{~d}$ before transport compared with calves born from cows of older parity. These effects might be explained by the combined effects of the difference in nutrient availability for uterine growth in late gestation between primiparous and multiparous cows (Carvalho et al., 2020) and the use of specific bulls for breeding heifers with favorable genetic parameters for ease of calving. Effects of maternal characteristics on future performance of calves are well reported in dairy cattle (Astiz et al., 2014; Pinedo and De Vries, 2017), but there are no studies in veal calves. Aside from the weight differences due to parity, there were no additional long-term effects of parity on health status and performance of calves. However, it might be interesting to investigate whether rearing regimens of calves at the dairy and veal farm need to be adjusted, or perhaps could be optimized, based on the parity of the dam.

\section{Effects of Calving Ease}

In the current study, ease of birth was only associated with the BW of calves $1 \mathrm{~d}$ before transport, but no significant effects of this factor were found on the clinical health status of calves. Previous studies have reported significant effects of ease of birth on postnatal health of calves (Barrier et al., 2012; Probo et al., 2012), but no studies investigated long-term effects of ease of birth in veal calves. The current experiment provided no support for the idea that ease of birth may have long-term consequences on health and performance of calves.

\section{Use of BW as an Indicator of Robustness}

Body weight of calves upon arrival at the veal farm is believed to be a reliable indicator of robustness (Marcato et al., 2018), because it has been associated with later risks of disease, in particular respiratory disorders (Brscic et al., 2012) and mortality at the veal farm. Recent observational studies showed that every $1 \mathrm{~kg}$ increase in BW of calves upon arrival is associated with a decreased hazard of mortality in the first 21 $\mathrm{d}$ (odds ratio $=0.93$; Renaud et al., 2018) and $78 \mathrm{~d}$ (odds ratio $=0.925 ;$ Goetz et al., 2021) at the veal farm, respectively. The current study showed that the difference in BW upon arrival between the 2 transport age groups was associated with a difference in several putative measures of robustness, including neutrophil and lymphocyte counts, levels and patterns of N-IgA and N-IgM (Marcato et al., 2022), the prevalence of individual treatments with medicines other than antibiotics, growth rate, and mortality risk. However, significant weight differences between other treatment groups of calves (e.g., between calves born from dams with different parities, or between calves born with or without assistance during calving) did not necessarily coincide with differences in any other putative measure of robustness. Likewise, a greater average weight upon arrival at the veal farm due to breed, such as, for example, was observed in Holstein Friesian $\times$ Belgian Blue crossbreds in comparison with Holstein Friesian calves, was not associated with significant differences in individual treatments with antibiotics or mortality risk. Therefore, the current study suggests that BW upon arrival per se might not be a reliable indicator or predictor of robustness, but should be considered in combination with other factors, such as age (which may likely be associated with underlying characteristics related to the development of the adaptive immune system) or breed (i.e., genetic background). The results of the current study clearly support previous findings that antimicrobial use is negatively related to carcass weight of calves at slaughter. Calves which received $>4$ individual antibiotic treatments had on average a 27.5 $\mathrm{kg}$ lower carcass weight compared with calves without antibiotic treatments. Pardon et al. (2013) demonstrated that for every $1 \%$ increase in antimicrobial drug use the carcass weight decreased by $1.5 \mathrm{~kg}$. In a previous 
study, the same negative relationship between carcass weight and the number of individual treatments with antibiotics was found (Marcato et al., 2020). In this latter study, the average carcass weight of calves receiving $>2$ treatments was $12.5 \mathrm{~kg}$ lower compared with that of calves with no treatments. Thus, whereas predicting robustness of calves based on BW upon arrival might be more complicated, retrospectively interpreting robustness of calves in terms of treatments with antibiotics based on differences in carcass weight seems to be feasible across factors such as age and breed.

\section{CONCLUSIONS}

This study showed that health and performance of veal calves were affected by transport age and breed. Transportation of calves from the dairy farm to the veal farm at $28 \mathrm{~d}$ of age resulted in a lower prevalence of calves treated individually with medicines other than antibiotics at the veal farm and a greater carcass weight compared with transportation at $14 \mathrm{~d}$ of age. Mortality risk at the veal farms was lower in calves transported at $28 \mathrm{~d}$ than in calves transported at $14 \mathrm{~d}$. More crossbreds other than Holstein Friesian $\times$ Belgian Blue calves received individual treatments with antibiotics and medicines other than antibiotics at the veal farm compared with Holstein Friesian $\times$ Belgian Blue calves. Collectively, these findings suggest a greater robustness of calves transported at $28 \mathrm{~d}$ of age in comparison with calves transported at $14 \mathrm{~d}$ of age. Additionally, breed may also be an important factor related to robustness of veal calves.

\section{ACKNOWLEDGMENTS}

This study was financially supported by Stichting Brancheorganisatie Kalversector (SBK, Nieuwegein, the Netherlands), ZuivelNL (the organization of the Dutch dairy sector, Den Haag, the Netherlands), and the Dutch Ministry of Agriculture, Nature and Food Quality (Den Haag, the Netherlands). The authors gratefully acknowledge Rimondia B.V. (Elspeet, the Netherlands) for providing personnel and laboratory support, all dairy and veal farmers who contributed to this experiment, and Van 't Slot Veetransport (Elspeet, the Netherlands) for expertly transporting the calves. The authors are also very grateful to Yvonne Daandels of ZLTO (Zuidelijke Land- en Tuinbouworganisatie, Den Bosch, the Netherlands), AERES Hogeschool Dronten (Dronten, the Netherlands), HAS Hogeschool (Den Bosch, the Netherlands), Gerald Lock and Harmen Kremers of Wageningen Bioveterinary Research (Lelystad, the Netherlands), and Theo van Hattum, Henk Gunnink, Joop van der Werf, Laura Arango Car- mona, Asri Wulansari, Amelia Florida Kiha, and Hao Ye (Wageningen University and Research, Wageningen, the Netherlands) for their help and assistance during the experiment. Moreover, we acknowledge the 2 anonymous reviewers for their valuable comments to previous versions of this paper. The authors have not stated any conflicts of interest.

\section{REFERENCES}

Astiz, S., A. Gonzalez-Bulnes, F. Sebastian, O. Fargas, I. Cano, and P. Cuesta. 2014. Maternal aging affects life performance of progeny in a Holstein dairy cow model. J. Dev. Orig. Health Dis. 5:374-384. https://doi.org/10.1017/S2040174414000361.

Autio, T., T. Pohjanvirta, R. Holopainen, U. Rikula, J. Pentikäinen, A. Huovilainen, H. Rusanen, T. Soveri, L. Sihvonen, and S. Pelkonen. 2007. Etiology of respiratory disease in non-vaccinated, non-medicated calves in rearing herds. Vet. Microbiol. 119:256265. https://doi.org/10.1016/j.vetmic.2006.10.001.

Bähler, C., A. Steiner, A. Luginbühl, A. Ewy, H. Posthaus, D. Strabel, T. Kaufmann, and G. Regula. 2012. Risk factors for death and unwanted early slaughter in Swiss veal calves kept at a specific animal welfare standard. Res. Vet. Sci. 92:162-168. https://doi .org/10.1016/j.rvsc.2010.10.009.

Barrier, A. C., E. Ruelle, M. J. Haskell, and C. M. Dwyer. 2012. Effect of a difficult calving on the vigour of the calf, the onset of maternal behaviour, and some behavioural indicators of pain in the dam. Prev. Vet. Med. 103:248-256. https://doi.org/10.1016/j .prevetmed.2011.09.001.

Baxter, E. M., S. Jarvis, J. Palarea-Albaladejo, and S. A. Edwards. 2012. The weaker sex? The propensity for male-biased piglet mortality. PLoS One 7:e30318. https://doi.org/10.1371/journal.pone .0030318 .

Berchtold, J. 2009. Treatment of calf diarrhea: Intravenous fluid therapy. Vet. Clin. North Am. Food Anim. Pract. 25:73-99. https:// doi.org/10.1016/j.cvfa.2008.10.001.

Brscic, M., H. Leruste, L. F. M. Heutinck, E. A. M. Bokkers, M. Wolthuis-Fillerup, N. Stockhofe, F. Gottardo, B. J. Lensink, G. Cozzi, and C. G. Van Reenen. 2012. Prevalence of respiratory disorders in veal calves and potential risk factors. J. Dairy Sci 95:2753-2764. https://doi.org/10.3168/jds.2011-4699.

Buss, L. N., T. T. Yohe, L. R. Cangiano, D. L. Renaud, A. J. Keunen, L. L. Guan, and M. A. Steele. 2021. The effect of neomycin inclusion in milk replacer on the health, growth, and performance of male Holstein calves during preweaning. J. Dairy Sci. 104:81888201. https://doi.org/10.3168/jds.2020-19827.

Carvalho, M. R., C. Aboujaoude, F. Peñagaricano, J. E. P. Santos, T. J. DeVries, B. W. McBride, and E. S. Ribeiro. 2020. Associations between maternal characteristics and health, survival, and performance of dairy heifers from birth through first lactation. J. Dairy Sci. 103:823-839. https://doi.org/10.3168/jds.2019-17083.

Chase, C. C., D. J. Hurley, and A. J. Reber. 2008. Neonatal immune development in the calf and its impact on vaccine response. Vet. Clin. North Am. Food Anim. Pract. 24:87-104. https://doi.org/10 .1016/j.cvfa.2007.11.001.

Clasen, J. B., A. Fogh, and M. Kargo. 2019. Differences between performance of $\mathrm{F}_{1}$ crossbreds and Holsteins at different production levels. J. Dairy Sci. 102:436-441. https://doi.org/10.3168/jds.2018 -14975 .

Clasen, J. B., E. Norberg, P. Madsen, J. Pedersen, and M. Kargo. 2017. Estimation of genetic parameters and heterosis for longevity in crossbred Danish dairy cattle. J. Dairy Sci. 100:6337-6342. https://doi.org/10.3168/jds.2017-12627.

Colditz, I. G., and B. C. Hine. 2016. Resilience in farm animals: Biology, management, breeding and implications for animal welfare. Anim. Prod. Sci. 56:1961-1983. https://doi.org/10.1071/AN15297.

Damiaans, B., V. Renault, S. Sarrazin, A. C. Berge, B. Pardon, S. Ribbens, C. Saegerman, and J. Dewulf. 2019. Biosecurity prac- 
tices in Belgian veal calf farming: Level of implementation, attitudes, strengths, weaknesses and constraints. Prev. Vet. Med. 172:104768. https://doi.org/10.1016/j.prevetmed.2019.104768.

de Almeida, A. M., M. Zachut, L. E. Hernández-Castellano, M. Šperanda, G. Gabai, and A. Mobasheri. 2019. Biomarkers of fitness and welfare in dairy animals: Healthy living. J. Dairy Res. 86:379-387. https://doi.org/10.1017/S0022029919000803.

Diana, A., M. Penasa, M. Santinello, F. Scali, E. Magni, G. L. Alborali, L. Bertocchi, and M. De Marchi. 2021. Exploring potential risk factors of antimicrobial use in beef cattle. Animal 15:100091. https://doi.org/10.1016/j.animal.2020.100091.

Engel, B., W. Buist, and C. G. van Reenen. 2016. Housing of calves in experimental facilities in relation to accuracy of comparison of feed rations in terms of confidence interval length and power of a significance test. Confidential report, commissioned by Denkavit Nederland BV.

Fiems, L. O. 2012. Double muscling in cattle: Genes, husbandry, carcasses and meat. Animals (Basel) 2:472-506. https://doi.org/10 $.3390 /$ ani2030472.

Fiems, L. O., J. L. De Boever, J. M. Vanacker, and D. L. De Brabander. 2013. Effect of cull potatoes in the diet for finishing Belgian Blue double-muscled cows. Animal 7:93-100. https://doi.org/10 $.1017 / \mathrm{S} 1751731112001036$.

Garcia, M., J. H. Shin, A. Schlaefli, L. F. Greco, F. P. Maunsell, J. E. P. Santos, C. R. Staples, and W. W. Thatcher. 2015. Increasing intake of essential fatty acids from milk replacer benefits performance, immune responses, and health of preweaned Holstein calves. J. Dairy Sci. 98:458-477. https://doi.org/10.3168/jds.2014 -8384 .

Goetz, H. M., D. F. Kelton, J. H. C. Costa, C. B. Winder, and D. L. Renaud. 2021. Identification of biomarkers measured upon arrival associated with morbidity, mortality, and average daily gain in grain-fed veal calves. J. Dairy Sci. 104:874-885. https://doi.org/10 3168/jds.2020-18729.

Hulbert, L. E., and S. J. Moisá. 2016. Stress, immunity, and the management of calves. J. Dairy Sci. 99:3199-3216. https://doi.org/10 $.3168 /$ jds.2015-10198.

Kenward, M. G., and J. H. Roger. 1997. Small sample inference for fixed effects from restricted maximum likelihood. Biometrics 53:983-997. https://doi.org/10.2307/2533558.

Marcato, F., H. van den Brand, B. Kemp, B. Engel, S. K. Schnabel, C. A. Jansen, V. P. M. G. Rutten, F. A. Hoorweg, A. Wulansari, M. Wolthuis-Fillerup, and K. van Reenen. 2022. Transport age and calf and dam characteristics affect immunoglobulin titers and hematological parameters of veal calves. J. Dairy Sci. 105:1432-1451. https://doi.org/10.3168/jds.2021-20636.

Marcato, F., H. van den Brand, B. Kemp, B. Engel, M. WolthuisFillerup, and K. van Reenen. 2020. Transport of young veal calves: Effects of pre-transport diet, transport duration and type of vehicle on health, behavior, use of medicines and slaughter characteristics. Front. Vet. Sci. 7:576469. https://doi.org/10.3389/fvets .2020 .576469 .

Marcato, F., H. van den Brand, B. Kemp, and K. van Reenen. 2018. Evaluating potential biomarkers of health and performance in veal calves. Front. Vet. Sci. 5:133. https://doi.org/10.3389/fvets.2018 .00133 .

Mee, J. F. 2008. Newborn dairy calf management. Vet. Clin. North Am. Food Anim. Pract. 24:1-17. https://doi.org/10.1016/j.cvfa 2007.10.002

Pardon, B., J. Alliët, R. Boone, S. Roelandt, B. Valgaeren, and P. Deprez. 2015. Prediction of respiratory disease and diarrhea in veal calves based on immunoglobulin levels and the serostatus for respiratory pathogens measured at arrival. Prev. Vet. Med. 120:169-176. https://doi.org/10.1016/j.prevetmed.2015.04.009.
Pardon, B., K. De Bleecker, M. Hostens, J. Callens, J. Dewulf, and P. Deprez. 2012. Longitudinal study on morbidity and mortality in white veal calves in Belgium. BMC Vet. Res. 8:26. https://doi.org/ 10.1186/1746-6148-8-26.

Pardon, B., M. Hostens, L. Duchateau, J. Dewulf, K. De Bleecker, and P. Deprez. 2013. Impact of respiratory disease, diarrhea, otitis and arthritis on mortality and carcass traits in white veal calves. BMC Vet. Res. 9:79. https://doi.org/10.1186/1746-6148-9-79.

Pempek, J., D. Trearchis, M. Masterson, G. Habing, and K. Proudfoot. 2017. Veal calf health on the day of arrival at growers in Ohio. J. Anim. Sci. 95:3863-3872.

Pinedo, P., and A. De Vries. 2017. Season of conception is associated with future survival, fertility, and milk yield of Holstein cows. J. Dairy Sci. 100:6631-6639. https://doi.org/10.3168/jds.2017-12662.

Pradhan, A., and P. E. Olsson. 2020. Sex differences in severity and mortality from COVID-19: Are males more vulnerable? Biol. Sex Differ. 11:53. https://doi.org/10.1186/s13293-020-00330-7.

Probo, M., A. Giordano, P. Moretti, G. Opsomer, L. Fiems, and M. Veronesi. 2012. Mode of delivery is associated with different hematological profiles in the newborn calf. Theriogenology 77:865-872. https://doi.org/10.1016/j.theriogenology.2011.09.010.

Renaud, D. L., T. F. Duffield, S. J. LeBlanc, S. Ferguson, D. B. Haley, and D. F. Kelton. 2018. Risk factors associated with mortality at a milk-fed veal calf facility: A prospective cohort study. J. Dairy Sci. 101:2659-2668. https://doi.org/10.3168/jds.2017-13581.

SBK. 2018. Protocol Gezonde Kalveren - Vitaal Kalf. Accessed Dec. 9, 2019. https://www.kalversector.nl/wp-content/uploads/2018 03/SBK-KVK-BIJL-700-02-20180401-Protocol-Gezonde-Kalveren .pdf. (in Dutch)

Smith, G. W. 2009. Treatment of calf diarrhea: Oral fluid therapy. Vet. Clin. North Am. Food Anim. Pract. 25:55-72. https://doi.org/10 .1016/j.cvfa.2008.10.006.

van Reenen, K. 2021. Supplemental Tables S1-S3.PDF. figshare. Journal contribution. https://doi.org/https://doi.org/10.6084/m9 .figshare.17024522.v1.

von Konigslow, T. E., D. L. Renaud, T. F. Duffield, C. B. Winder, and D. F. Kelton. 2020. Assessing the utility of leukocyte differential cell counts for predicting morbidity, mortality, and growth in a grain-fed veal facility: A prospective single cohort study. J. Dairy Sci. 103:9332-9344. https://doi.org/10.3168/jds.2020-18532.

Wilson, L. L., J. L. Smith, D. L. Smith, D. L. Swanson, T. R. Drake, D. R. Wolfgang, and E. F. Wheeler. 2000. Characteristics of veal calves upon arrival, at 28 and 84 days, and at end of the production cycle. J. Dairy Sci. 83:843-854. https://doi.org/10.3168/jds .S0022-0302(00)74948-4.

Zarulli, V., J. A. Barthold Jones, A. Oksuzyan, R. Lindahl-Jacobsen, K. Christensen, and J. W. Vaupel. 2018. Women live longer than men even during severe famines and epidemics. Proc. Natl. Acad. Sci. USA 115:E832-E840. https://doi.org/10.1073/pnas .1701535115 .

\section{ORCIDS}

F. Marcato (1) https://orcid.org/0000-0002-7063-5955

H. van den Brand $\odot$ https://orcid.org/0000-0003-0477-169X

B. Kemp 이 https://orcid.org/0000-0002-9765-9105

B. Engel ๑ https://orcid.org/0000-0002-7680-326X

S. K. Schnabel $\odot$ https://orcid.org/0000-0003-2338-3019

M. Wolthuis-Fillerup (1) https://orcid.org/0000-0001-9226-0368

K. van Reenen ๑ https://orcid.org/0000-0003-0356-9350 